\title{
Patient adherence, compliance, and perspectives on evolocumab for the management of resistant hypercholesterolemia
}

This article was published in the following Dove Press journal:

Patient Preference and Adherence

\author{
Constantine E Kosmas \\ Delia Silverio ${ }^{2}$ \\ Julio Ovalle ${ }^{2}$ \\ Peter D Montan ${ }^{2}$ \\ Eliscer Guzman ${ }^{3}$ \\ 'Division of Cardiology, Department \\ of Medicine, Mount Sinai Hospital, \\ New York, NY, USA; ${ }^{2}$ Cardiology \\ Clinic, Cardiology Unlimited, PC, \\ New York, NY, USA; ${ }^{3}$ Division of \\ Cardiology, Department of Medicine \\ Montefiore Medical Center, Bronx, \\ NY, USA
}

\begin{abstract}
Evolocumab is a PCSK9 inhibitor which is administered subcutaneously, and when added to statin therapy it has been shown to cause a significant incremental LDL-C reduction, leading to a reduction of cardiovascular risk. Evolocumab has a favorable side effect profile, and its self-administration at home appears to be safe and effective with the appropriate training and instructions from a health care provider. Current studies are showing encouraging results regarding adherence to evolocumab in real-life settings, and adherence rates to evolocumab appear to be better than those to statins. However, further larger studies are needed for a more definitive assessment of the short- and long-term patient adherence rates to evolocumab. In addition, reductions in the price of evolocumab may also be necessary to improve cost-effectiveness of the drug.

Keywords: evolocumab, adherence, hypercholesterolemia, cardiovascular risk
\end{abstract}

\section{Introduction}

Extensive evidence shows that low-density lipoprotein cholesterol (LDL-C)-lowering therapy has beneficial effects in decreasing cardiovascular risk in both primary and secondary prevention. ${ }^{1-4}$

Statins are the standard of care for LDL-C lowering; however, several patients develop statin intolerance due to side effects, especially myalgias and weakness. ${ }^{5,6}$ Furthermore, even with high-intensity statin therapy, some patients cannot achieve the desired LDL-C goal, and therefore remain at high risk for cardiovascular events. ${ }^{7.8}$ Because of that, extensive research has been conducted to find additional agents with an acceptable side effect profile that could cause significant reduction of LDL-C levels.

Proprotein convertase subtilisin/kexin type 9 (PCSK9) inhibitors represent a relatively new class of LDL-C-lowering agents, which act by blocking the activity of PCSK9 and thus reducing the degradation of LDL receptors and increasing the clearance of LDL-C. ${ }^{9-11}$ Evolocumab is a monoclonal antibody which inhibits PCSK9 and is administered subcutaneously in biweekly or monthly intervals. In the FOURIER trial, which had a follow-up period of 2.2 years, evolocumab, when added to the statin therapy, was shown to cause an additional reduction of LDL-C levels by $59 \%$. More importantly, evolocumab decreased the composite of cardiovascular death, myocardial infarction, or stroke by $20 \% .^{12}$

Notwithstanding, the benefits of the treatment with evolocumab will only be replicated in real-life if patients accept, adhere, and comply with the prescribed treatment regimen. It would be very important here to point out that in the case of statins, their real-life effectiveness is significantly compromised by poor adherence and compliance. ${ }^{13-15}$
Correspondence: Constantine E Kosmas Division of Cardiology, Department of Medicine, Mount Sinai Hospital, 168-24 Powells Cove Blvd, Beechhurst, New York, NY I I357, USA

Tel +l 6467347969

Email cekosmasI@gmail.com 
Thus, our review aims to focus on patient adherence, compliance, and perspectives on evolocumab for the management of resistant hypercholesterolemia.

\section{Patient adherence and compliance}

Medication compliance is the act of taking medication on schedule or taking medication as prescribed; however, recently, this term has fallen into disfavor. Medication adherence is the act of filling new prescriptions or refilling prescriptions on time, and this term better represents the more complex interplay among patient, provider, and medication and reflects the fact that following a medication regimen is not necessarily a simple choice. ${ }^{16}$

The lack of adherence to cardiovascular medications in real-life settings leads to poor clinical outcomes, as it increases the risk for hospitalization and mortality, particularly in high-risk patients. ${ }^{17,18}$

With regard to statins, it is well established that statin therapy decreases mortality in high cardiovascular risk patients in both primary and secondary prevention. ${ }^{19,20} \mathrm{How}-$ ever, studies have reported poor adherence to statin therapy, which has been attributed to the patients' lack of knowledge about the efficacy of the statin therapy, statin intolerance, or fear about possible side effects..$^{21,22}$ Here, it has to be stressed that poor adherence and compliance to statins come with a heavy toll, as they lead to significant increases in total mortality, as well as cardiovascular morbidity and mortality. ${ }^{13-15}$

In this context, due to its acceptable side effect profile, reduced dosing frequency, and the availability of easy-to-use and effective devices for self-administration, evolocumab brings opportunities to improve the adherence to lipid-lowering therapy. Here it has to be mentioned that, in contrast to other drug classes (eg, antiplatelet agents, the effect of which is not easy to routinely monitor), monitoring of adherence to PCSK9 inhibitors is a relatively easy task in view of their profound LDL-C-lowering effect.

In this regard, studies have shown overall satisfactory results with respect to patient's adherence to PCSK9 inhibitors (including evolocumab) in real-life settings. More specifically, in a small retrospective analysis, the level of full adherence to PCSK9 inhibitors was found to be higher than statins (79.4\% vs $30.9 \%$, respectively), although the difference did not reach statistical significance due to the small number of subjects. ${ }^{23}$ In another small study, which examined the real-world effectiveness and safety of PCSK9 inhibitors (evolocumab and alirocumab), the LDL-C reductions obtained with PCSK9 inhibitors in clinical practice were found to be similar to those described in clinical trials
(50\%-70\%). PCSK9 inhibitors were well tolerated and there were no discontinuations due to side effects. ${ }^{24}$

Thus, based on the above, evolocumab appears to be in general well tolerated, effective, and with a low rate of reported side effects. However, in-depth patient education, close supervision, and regular follow-up are strongly recommended in order to optimize adherence and compliance to therapy. ${ }^{25,26}$

Notwithstanding, even though current studies are showing encouraging results regarding adherence to evolocumab (and PCSK9 inhibitors in general) in real-life settings, there are still insufficient data and further larger studies are needed to evaluate the short- and long-term patient adherence rates to these medications.

\section{Acceptability and perspective on evolocumab therapy}

While evolocumab is available only via subcutaneous administration, studies have revealed that the selfadministration of evolocumab at home is safe and effective with the appropriate training and instructions from a health care provider. More specifically, patients were successful in self-administering evolocumab in the home-use setting in approximately $95 \%$ of attempts and achieved LDL-C reductions from baseline to week 6 or the mean of weeks 10 and 12 of approximately $65 \%$. Rates of successful selfadministration and LDL-C reduction were similar across dosing schedules and study devices. ${ }^{27}$

Furthermore, the choice of the monthly (QM) or twice weekly (Q2W) dosing regimen does not appear to be associated with any significant differences in adherence, acceptability or patients' preferences. In a study, which included 2,318 patients ( $59 \%$ initially randomized to the QM regimen and $41 \%$ initially randomized to the Q2W regimen), $74 \%$ of those initially randomized to the QM regimen chose to continue with QM dosing and 26\% decided to switch to the Q2W regimen. Similarly, from those initially randomized to the Q2W regimen, 70\% chose to continue with Q2W dosing and $30 \%$ opted to switch to QM dosing. Only $2 \%$ of patients in the QM regimen and 2\% of patients in the Q2W regimen did not receive any further doses following the first day of administration. More importantly, following initial decisions regarding dosing preference, patients did not generally choose to change their regimen further during ongoing treatment, as only $5 \%$ of QM patients and $8 \%$ of Q2W patients switched to the alternative dosing regimen. ${ }^{28}$

One of the main barriers for patient's access and appropriate continuation of the evolocumab therapy is the difficulty in 
obtaining insurance coverage, which is mostly due to the high cost of the medication. Studies have indicated a mean annual wholesale price for evolocumab as high as \$14,100 and have reached the conclusion that assuming 2015 prices, PCSK9 inhibitor use in patients with heterozygous familial hypercholesterolemia or atherosclerotic cardiovascular disease did not meet generally acceptable incremental cost-effectiveness thresholds and was estimated to increase US health care costs substantially. ${ }^{29}$ This was confirmed by another recent study, which showed that at current prices, the addition of PCSK9 inhibitors to statin therapy was estimated to provide an additional quality-adjusted life year for $\$ 337,729$ and that significant discounts were necessary to meet conventional cost-effectiveness standards. ${ }^{30,31}$ On the other hand, the National Institute for Health and Care Excellence in the UK has approved the limited use of PCSK9 inhibitors in certain high-risk patient groups, although these National Institute for Health and Care Excellence results were based on undisclosed price discounts negotiated with the pharmaceutical companies. ${ }^{31,32}$ In a recent study, which examined the cost-effectiveness of PCSK9 inhibitors vs ezetimibe through LDL-C reductions in a Norwegian setting, it was shown that high lifetime costs of PCSK9 inhibitors may not be offset by estimated health gains for most eligible patients, and PCSK9 inhibitors were found to be cost-effective only in secondary prevention for older patients with high absolute risk of cardiovascular disease. However, the authors did point out that this picture was likely to change as price of this class of medications decreases. ${ }^{33}$ Finally, in a very recent Canadian study, despite the critical assumption that evolocumab may reduce mortality over time, it was shown that the drug was unlikely to be cost-effective for secondary prevention at current Canadian prices. ${ }^{34}$

Given the above, the treatment with evolocumab presents an initial therapy coverage denial by insurance companies as high as $80 \%$, even when the US Food and Drug Administration-approved indications for the therapy have been met by the patient. Furthermore, only $46.6 \%$ of Medicare patients and $26.7 \%$ of privately insured patients subsequently gained approval after extensive appeals. ${ }^{35}$

In order to improve cost-effectiveness, the manufacturer of evolocumab offered a money-back guarantee by fully refunding the drug's cost, under certain conditions, if a patient being treated with evolocumab is hospitalized with either a myocardial infarction or stroke. However, despite this improved outcomes-based pricing, the incremental costeffectiveness ratio for a PCSK9 inhibitor added to a statin was only marginally improved. Even in the best scenario, in which the manufacturer would refund drug costs plus inpatient costs for myocardial infarction or stroke, the incremental cost-effectiveness ratio for a PCSK9 inhibitor added to a statin improved by only $3.1 \%{ }^{36}$

\section{Conclusion and future directions}

From the above data, it becomes evident that evolocumab is a promising PCSK9 inhibitor that causes significant LDL-C reductions and decreases cardiovascular risk. Although current studies are showing encouraging results regarding adherence to evolocumab in real-life settings, further larger studies are needed for a more definitive assessment of the short- and long-term patient adherence rates. In-depth patient education, close supervision, and regular follow-up are important factors to optimize adherence to therapy. Reductions in the price of evolocumab may also be necessary to improve cost-effectiveness of the drug.

Inclisiran is a long-acting small interfering RNA (siRNA) molecule directed against PCSK9, and it has been shown to significantly decrease hepatic production of PCSK9 and cause a marked reduction in LDL-C levels. ${ }^{37}$ This agent is not licensed as yet and has not been proven to reduce cardiovascular outcomes, as of now. However, inclisiran appears very promising and, in the future, if approved, its use may lead to a significant improvement in adherence and compliance due to its very infrequent, 6-monthly dosing intervals.

\section{Disclosure}

Dr Constantine E Kosmas reports personal fees from Amgen, outside the submitted work. Dr Eliscer Guzman reports personal fees from Amgen Inc., outside the submitted work. Dr Kosmas and Dr Guzman are members of the Dyslipidemia Speaker Bureau of Amgen, Inc. The authors report no other conflicts of interest in this work.

\section{References}

1. Vallejo-Vaz AJ, Robertson M, Catapano AL, et al. Low-Density Lipoprotein Cholesterol Lowering for the Primary Prevention of Cardiovascular Disease Among Men With Primary Elevations of Low-Density Lipoprotein Cholesterol Levels of $190 \mathrm{mg} / \mathrm{dL}$ or Above: Analyses From the WOSCOPS (West of Scotland Coronary Prevention Study) 5-Year Randomized Trial and 20-Year Observational Follow-Up. Circulation. 2017;136(20):1878-1891.

2. Reiner Ž. Statins in the primary prevention of cardiovascular disease. Nat Rev Cardiol. 2013;10(8):453-464.

3. Koskinas KC, Siontis GCM, Piccolo R, et al. Effect of statins and non-statin LDL-lowering medications on cardiovascular outcomes in secondary prevention: a meta-analysis of randomized trials. Eur Heart J. 2018;39(14):1172-1180.

4. Grundy SM. Promise of low-density lipoprotein-lowering therapy for primary and secondary prevention. Circulation. 2008;117(4):569-573. 
5. Cohen JD, Brinton EA, Ito MK, Jacobson TA. Understanding Statin Use in America and Gaps in Patient Education (USAGE): an internetbased survey of 10,138 current and former statin users. J Clin Lipidol. 2012;6(3):208-215.

6. Reiner Z. Resistance and intolerance to statins. Nutr Metab Cardiovasc Dis. 2014;24(10):1057-1066.

7. Ridker PM, Mora S, Rose L; JUPITER Trial Study Group. Percent reduction in LDL cholesterol following high-intensity statin therapy: potential implications for guidelines and for the prescription of emerging lipid-lowering agents. Eur Heart J. 2016;37(17):1373-1379.

8. Wong ND, Chuang J, Wong K, Pham A, Neff D, Marrett E. Residual dyslipidemia among United States adults treated with lipid modifying therapy (data from National Health and Nutrition Examination Survey 2009-2010). Am J Cardiol. 2013;112(3):373-379.

9. Page MM, Watts GF. PCSK9 inhibitors - mechanisms of action. Aust Prescr. 2016;39(5):164-167.

10. Reiner Ž. PCSK9 inhibitors - past, present and future. Expert Opin Drug Metab Toxicol. 2015;11(10):1517-1521.

11. Reiner Ž. PCSK9 inhibitors in clinical practice: Expectations and reality. Atherosclerosis. 2018;270:187-188.

12. Sabatine MS, Giugliano RP, Keech AC, et al. FOURIER Steering Committee and Investigators. Evolocumab and Clinical Outcomes in Patients with Cardiovascular Disease. $N$ Engl J Med. 2017;376(18): $1713-1722$.

13. Lardizabal JA, Deedwania PC. Benefits of statin therapy and compliance in high risk cardiovascular patients. Vasc Health Risk Manag. 2010;6: $843-853$.

14. Ford I, Murray H, Packard CJ, Shepherd J, Macfarlane PW, Cobbe SM. West of Scotland Coronary Prevention Study Group. Long-term follow-up of the West of Scotland Coronary Prevention Study. N Engl J Med. 2007;357(15):1477-1486.

15. Ho PM, Magid DJ, Shetterly SM, et al. Medication nonadherence is associated with a broad range of adverse outcomes in patients with coronary artery disease. Am Heart J. 2008;155(4):772-779.

16. Miller LG, Hays RD. Adherence to combination antiretroviral therapy: synthesis of the literature and clinical implications. AIDS Read. 2000; 10(3):177-185.

17. Kolandaivelu K, Leiden BB, O'Gara PT, Bhatt DL. Non-adherence to cardiovascular medications. Eur Heart J. 2014;35(46):3267-3276.

18. Baroletti S, dell'orfano $\mathrm{H}$. Medication adherence in cardiovascular disease. Circulation. 2010;121(12):1455-1458.

19. Nunes JP. Statins in primary prevention: impact on mortality. A metaanalysis study. Minerva Cardioangiol. 2017;65(5):531-538.

20. Rodriguez F, Maron DJ, Knowles JW, Virani SS, Lin S, Heidenreich PA. Association Between Intensity of Statin Therapy and Mortality in Patients With Atherosclerotic Cardiovascular Disease. JAMA Cardiol. 2017;2(1):47-54.

21. Bates TR, Connaughton VM, Watts GF. Non-adherence to statin therapy: a major challenge for preventive cardiology. Expert Opin Pharmacother. 2009;10(18):2973-2985.

22. Wouters H, van Dijk L, Geers HC, et al. Understanding Statin NonAdherence: Knowing Which Perceptions and Experiences Matter to Different Patients. PLoS One. 2016;11(1):e0146272.
23. Gragnano F, Concilio C, Cesaro A, et al. P1513Adherence to PCSK9 inhibitors in high cardiovascular risk patients in real-world setting: results from a single-center experience and comparison with statin therapy. Eur Heart J. 2017;38(suppl_1):P1513.

24. Torres PR, Portilla AJ, Gonzalez MO, et al. 5PSQ-025 Real-world effectiveness and safety of evolocumab and alirocumab. Eur J Hosp Pharm. 2018;25:A176.

25. Saborowski M, Dölle M, Manns MP, Leitolf H, Zender S. Lipid-lowering therapy with PCSK9-inhibitors in the management of cardiovascular high-risk patients: Effectiveness, therapy adherence and safety in a real world cohort. Cardiol J. 2018;25(1):32-41.

26. Graesdal A, Dybvig A. Real-life PCSK9 experience: Efficacy, compliance and side effects after one year treatment in familial hypercholesterolemia patients. J Am Coll Cardiol. 2018;71(11):A1754.

27. Dent R, Joshi R, Stephen Djedjos C, et al. Evolocumab lowers LDL-C safely and effectively when self-administered in the at-home setting. Springerplus. 2016;5:300

28. Boccara F, Dent R, Ruilope L, Valensi P. Practical considerations for the use of subcutaneous treatment in the management of Dyslipidaemia. Adv Ther. 2017;34(8):1876-1896.

29. Kazi DS, Moran AE, Coxson PG, et al. Cost-effectiveness of PCSK9 Inhibitor Therapy in Patients With Heterozygous Familial Hypercholesterolemia or Atherosclerotic Cardiovascular Disease. JAMA. 2016; 316(7):743-753.

30. Arrieta A, Hong JC, Khera R, Virani SS, Krumholz HM, Nasir K. Updated Cost-effectiveness Assessments of PCSK9 Inhibitors From the Perspectives of the Health System and Private Payers: Insights Derived From the FOURIER Trial. JAMA Cardiol. 2017;2(12): 1369-1374.

31. Kosmas CE, Dejesus E, Morcelo R, Garcia F, Montan PD, Guzman E. Lipid-lowering interventions targeting proprotein convertase subtilisin/ kexin type 9 (PCSK9): an emerging chapter in lipid-lowering therapy. Drugs Context. 2017;6:212511.

32. National Institute for Health and Care Excellence. Evolocumab for Treating Primary Hypercholesterolaemia and Mixed Dyslipidaemia. London: National Institute for Health and Care Excellence; 2016.

33. Korman M, Wisløff T. Modelling the cost-effectiveness of PCSK9 inhibitors vs. ezetimibe through LDL-C reductions in a Norwegian setting. Eur Heart J Cardiovasc Pharmacother. 2018;4(1):15-22.

34. Lee TC, Kaouache M, Grover SA. Evaluation of the cost-effectiveness of evolocumab in the FOURIER study: a Canadian analysis. CMAJ Open. 2018;6(2):E162-E167.

35. Baum SJ, Toth PP, Underberg JA, Jellinger P, Ross J, Wilemon K. PCSK9 inhibitor access barriers-issues and recommendations: Improving the access process for patients, clinicians and payers. Clin Cardiol. 2017;40(4):243-254

36. Kazi DS, Penko J, Ollendorf DA, Coxson PG, Bibbins-Domingo K. Effect of Money-Back Guarantees on the Cost-Effectiveness of Proprotein Convertase Subtilisin/Kexin Type 9 Inhibitors. Ann Intern Med. 2018;168(12):896-898.

37. Kosmas CE, Muñoz Estrella A, Sourlas A, et al. Inclisiran: A New Promising Agent in the Management of Hypercholesterolemia. Diseases. 2018;6(3):63.
Patient Preference and Adherence

\section{Publish your work in this journal}

Patient Preference and Adherence is an international, peer-reviewed, open access journal that focuses on the growing importance of patient preference and adherence throughout the therapeutic continuum. Patient satisfaction, acceptability, quality of life, compliance, persistence and their role in developing new therapeutic modalities and compounds to optimize

\section{Dovepress}

clinical outcomes for existing disease states are major areas of interest for the journal. This journal has been accepted for indexing on PubMed Central. The manuscript management system is completely online and includes a very quick and fair peer-review system, which is all easy to use. Visit http://www. dovepress.com/testimonials.php to read real quotes from published authors. 